\title{
Vulva Cancer Treatment with Cryosurgery
}

\author{
Mauro $\mathrm{JE}^{1 *}$, Storino $\mathrm{C}^{2}$, Bianconi $\mathrm{MI}^{3}$, Farah $\mathrm{C}^{4}$ and $\mathrm{D}^{\prime}$ Atri $\mathrm{FJ}^{5}$ \\ Department of Gynecology and Oncology, Carlos G Durand Hospital, Argentina
}

\begin{abstract}
Vulvar cancer represents $4 \%$ to $5 \%$ of Low Genital Tract Tumors (LGTT) and $1 \%$ of all cancers in women. Treatment depends on stage, and when possible surgery is preferable. Advanced cancers require large resections (with needs grafts and-or rotating flaps), radio and/or chemotherapy, all of which can lead to high morbidity and quality of life impairment. To minimize these effects, in 1994, we developed a cryosurgery prospective protocol to manage vulvar cancer in patients with comorbid conditions.
\end{abstract}

Patients and Methods: Between 1994 and 2019 we treated $n=41$ patients: FIGO stages I: $n=2$ (4.88\%) II: $\mathrm{n}=9$ (21.95\%), III: $\mathrm{n}=28$ (68.29\%), IV: $\mathrm{n}=2$ (4.88\%). Median age 64.3 (28 to 90 years old), and $70 \%$ were 70 years old or older, $59 \%$ had severe comorbidities (diabetes, autoimmune diseases, immunosuppressive user).

Cryosurgery Protocol: Firstly, tumor resection, hemostasis, and 2 rapid freezing- slow thawing cycles with Liquid Nitrogen (LN) spray. The cycles should include the logde and a $1.5 \mathrm{~cm}$ safety margin. After complete healing (between 45 and 95 days after cryosurgery), nodes are treated according to FIGO stages.

Result: All patients after the effects of the anesthesia were able to urinate spontaneously, walk, had minimal analgesic requirements, with good postoperative. The patients remained in the hospital for one or two days, and with rare exceptions, were discharged the following day with controls twice a week at the hospital. None of the patients required flaps or grafts to repair the treated areas. After complete healing they maintained the vulvar sensitivity and considerably improved their quality of life. Some of them, who had a partner, were able to resume their sexual intercourse.

OPEN ACCESS

*Correspondence:

Mauro Juana Elida, Department of Gynecology and Oncology, Carlos $G$ Durand Hospital, Av. Del Golf 1805, Barrio Islas del Golf, Edificio Acqua II, Piso 6 Dto 606, Nordelta, Tigre, Buenos Aires, Argentina, Tel: +54-11-4401-

4080;

E-mail: jmauro@intramed.net Received Date: 04 Dec 2020 Accepted Date: 07 Jan 2021 Published Date: 22 Jan 2021

Citation:

Mauro JE, Storino C, Bianconi MI,

Farah C, D'Atri FJ. Vulva Cancer Treatment with Cryosurgery. J Gynecol Oncol. 2021; 4(1): 1050

Copyright $\odot 2021$ Mauro JE. This is an open access article distributed under

the Creative Commons Attribution

License, which permits unrestricted use, distribution, and reproduction in any medium, provided the original work is properly cited.
Mean follow-up: 55.39 (3 months to 258 months). Five patients had local recurrences between 12 and 72 months after treatment, and were controlled with a new cryosurgery. Six patients had HPV related lesions located in other areas of the lower genital tract, which were also controlled with cryosurgery. Twenty five of them died 19 due to an unrelated cause of death, and 6 due to disease progression in the nodes without vulvar recurrence, 9 patients survived and were free of disease with a mean follow-up of 53 months. Seven patients, after a disease free follow up of 17.2 months, weren't able to be controlled, as they lived more than $400 \mathrm{~km}$ way from the hospital. Local control was achieved in all patients.

Comments: Cryosurgery can be done after any previous treatment, and can be repeated to control recurrences.

Conclusion: Given the simplicity of the technique, its low cost, the possibility of being used in patients with multiple co-morbidities, the absence of major complications, and the anatomical and functional results obtained, we believe that cryosurgery can be considered among the best options to control of vulvar cancer, even large or advanced cases, in elderly patients and-or with severe comorbidities.

\section{Keywords: Cryoablation; Low genital tract tumors; Innovative technique}

\section{Introduction}

Vulvar cancer represents $4 \%$ to $5 \%$ of tumors of the Low Genital Tract (LGT) and $1 \%$ of all cancers in women. They have different therapeutic options according to their location, extension (stage) and histological grade. Treatment depends on the stage, and when possible, surgery is preferable. Conventional surgery varies in extension and can be more or less radical according to the Federation International of Gynecology and Obstetrics (FIGO) stage. The surgical resection must include the tumor plus a safety margin. In advanced cancers, radiotherapy is an option, associated or not with concurrent chemotherapy or other techniques. Advanced cancers require large resections, which 
often need grafts and/or rotating flaps. Postoperative infections are frequent and difficult to treat, because most patients present multiple co-morbidities and severe immunodeficiency, which significantly lengthen the final recovery.

The mentioned treatments can produce serious adverse effects: Devastating effects on anatomy and function, alterations in the patient's sexuality, self-esteem, and overall diminished Quality of Life (QOL); which can also affect the patient's partner. Treatment can contribute to a sense of loss of control over one's body and anxiety concerning personal and genital health, can influence body image and self-esteem, and can raise questions of trust and loyalty in sexual partnerships. All of these factors can be detrimental for a woman's emotional, sexual and overall well-being. These effects have been described also after the treatment of vulvar dysplasia, being much more important post-treatment of vulvar cancer [1]. Core areas usually require more time to shed.

To improve these results, and encouraged by results obtained in another medical areas, which were added more and more over time from the fields of dermatology [2-5], urology [6-11], lung tumors [12-17], breast [18-21], vulva [22-26], esophagus [27], pancreas [28-31], basic [32-35], prostate [36-40], and liver [33,34,41], hepatic metastases [42] head and neck [43] among others, and then also for the greater knowledge of the effects of cryosurgery (also known as cryo-ablation or cryo-therapy).

In 1994 we incorporated cryosurgery as an IRB approved Research protocol for controlling vulvar cancer, where all these effects were minimized [26,43-46]. Until that date the use of cryosurgery in Gynecology in Argentina, was limited to Intraepithelial Lesions of the cervix (IEL).

Our objective is to describe the results after treatment with cryosurgery in patients with neoplastic vulvar lesions, in terms of disease control, QOL and sexuality.

\section{According to John M. Baust et al. [47],}

- $\quad$ "Thermal ablation therapies are currently used for cancer treatment, and they are applied with the intention of healing. They provide promising success rates, often superior to "gold standard" approaches. It is said that expectation for cancer cure can be enhanced by a better understanding of the thermal effects on cancer cells and host tissue, and the molecular mechanisms of cancer cell mutations, that allow resistance to therapy."

In addition, with the enormous technological advances in images, computing etc., Sandison et al. [48],

- $\quad$ "Treatments specifically designed for each particular case can be performed. These methods allow visualizing the anatomy, guiding the insertion of the thermal probes and temperature sensors, achieving the elective destruction of the affected areas, and keeping the neighboring areas healthy".

In our experience with the treating of vulvar cancer, we observed only 5/41 cases of small local recurrences that could have been controlled with new cryosurgery, since it does not induce any type of tumor resistance, as is also observed with other thermal techniques: radiofrequency, microwave, High Intensity Focused Ultrasound (HIFU), and laser.

Currently, cryosurgery is defined as "the controlled destruction of cells and tissues by extremely low temperatures". It is well known that conventional surgery is based on resection. Cryosurgery differs from this technique, because allows to resect only macroscopically visible areas of the tumor, leading to a much more conservative treatment. Lodge and safety margins are treated by freezing, leaving tissues in situ, allowing a very different local result and other important changes. The temperature achieved and the way to reach it, are fundamental because they produce completely different results.

\section{Material and Methods}

\section{Design}

This is a Prospective open study. Case series 1994 IRB approved CODEI (Teaching and Research Committee) and Ethics Durand Hospital.

\section{Population}

Patients with neoplastic vulvar lesions underwent cryosurgery between 1994 to 2019 in Gynecology Department Carlos G. Durand Hospital, Buenos Aires, Argentina. We treated 41 patients (Table 1): Stages FIGO I: 2 patients (4.88 \%), II: 9 patients (21.95 \%), III: 28 patients (68.29\%), IV: 2 patients (4.88\%). Average age of 64.3 years old (28 to 90), 24 of them (59\%) suffering from severe comorbidities (DBT, autoimmune diseases, HIV, immunosuppressive user). 49\% of overall patients surpassing the age of 70 . Histology 38 squamous cell carcinomas ( 1 warty variety), 2 basal cell carcinomas, and 1 adenocarcinoma (Table 1).

\section{Assessment tools}

Consists of: 1) Usual complete clinical history, 2) Colposcopy: Which includes: Inspection without preparation to evaluate the vaginal content, washing with physiological solution and colposcopic examination without and with green filter, then with acetic acid at $5 \%$ and Schiller's test with lugol solution. It is very important to respect this specific order: if we perform the acetic acid test first, it can happen that VAIN lesions, which sometimes are only represented by small red spots of different sizes (vessels), disappear because acetic acid produces vasoconstriction, and can remain unnoticed. We can also avoid sub-diagnosis by examining carefully the four vaginal sacks, vaginal walls completely; and the angles of the vault after a hysterectomy. This examination must be complete in each from the cervix to the vulva and perineum. 3) In perianal lesions, anal canal cytology and high-resolution anoscopy are performed. 4) Careful palpation of the entire low genital tract, looking for the presence of indurations, irregularities in the surface, fixation to underlying tissues, ulcerations or any other sign that may suggest further lesion. 5) Biopsy of the suspicious areas detected, sent for the pathological study, with a scheme of the different samples to identify the exact extraction position. 6) Routine pre-surgical studies and abdominal and pelvic computed tomography. Depending on the stage, other studies according to FIGO standards. 7) Female sexual function index: Sf-36 (quality of life), Global assessment question, Visual analog scale for pain and sensitivity [49]. 8) Informed consent. Explanation of therapeutic options, along with routine pre-surgical studies, we deliver a brief explanation of the technique, postoperative controls, Table 1: Patients $n^{\circ}=41$.

\begin{tabular}{|c|c|c|c|c|c|c|}
\hline \multirow{2}{*}{ Age (years) } & \multirow{2}{*}{ Age $\geq 70$} & \multirow{2}{*}{${ }^{*}$ Co-morbid. } & \multicolumn{4}{|c|}{ FIGO STAGE } \\
\cline { 4 - 7 } & & & I & II & III & IV \\
\hline 64.3 & 20 & 24 & 2 & 9 & 28 & 2 \\
\hline 28 to 90 & $49 \%$ & $59 \%$ & $4.88 \%$ & $21.95 \%$ & $68.30 \%$ & $4.88 \%$ \\
\hline
\end{tabular}

${ }^{*}$ Comorbidities: Diabetes; Hypertension; Auto immune diseases; HIV; Transplants etc 


\begin{tabular}{|c|c|c|c|c|c|}
\hline \multirow[b]{2}{*}{ Follow-up (months) } & \multirow[b]{2}{*}{ Recurrences } & \multicolumn{4}{|c|}{ Local control in vulva $100 \%$} \\
\hline & & \multicolumn{2}{|r|}{ Death } & $\begin{array}{l}\text { Loss of control after } 17 \\
\text { months }\end{array}$ & Survived free of disease \\
\hline 58 & ${ }^{* *} 5$ & 19 & 6 & 7 & 9 \\
\hline 6 to 258 & $12 \%$ & $46 \%$ & $15 \%$ & $17 \%$ & $22 \%$ \\
\hline
\end{tabular}

${ }^{* *}$ treated with cryosurgery again with local control

expected results, etc. A written copy of all this information is given to the patient, to be read at home, and to be signed in the following consultation, in the presence of a doctor. There was no control group because, after presenting the therapeutic options, none of the patients accepted conventional surgery. We gathered an interesting number of patients.

\section{Technique}

After obtaining a definitive diagnosis in each area of LGT, the technique used has some variants depending if the patient also presents others lesions: Condyloma, Intraepithelial Lesions (IEL), or multicenter cancer. Many times several types of lesions coexist simultaneously or successively in the same patient: Importance of a careful and complete preoperative evaluation. The procedure is performed under epidural anesthesia. We remove the whole piece in block but without safety margin, because it will only be treated with cryosurgery. Resection is mandatory to reduce surgery time and postoperative period. Then, hemostasis and 2 freeze-thaw cycles. Freezing includes the lodge and the safety margin and, if indicated, the lower third of the urethra. Quick freezing should be performed at temperatures below $-50^{\circ} \mathrm{C}$ (centigrade degrees below zero). Then this temperature must be kept at least for $5 \mathrm{~min}$ to $10 \mathrm{~min}$. Finally, the thawing should be spontaneous, avoiding sources of heat (such as lights). This cycle is repeated 2 times. This temperature can be achieved using gases in liquid state; such as nitrogen, argon and helium, among others. We only used liquid nitrogen. When the area to be treated is large, it must be performed by sectors, because the freezing must be fast. Then it is extended until it completely covers the previously defined area. Safety margins of $1.5 \mathrm{~cm}$ must be respected in all the edges of the lesion. The sides are easily evaluated by simple inspection, not the margin in depth. This can be evaluated by palpation, since the frozen tissue acquires solid consistency that differs clearly from the non-frozen; or by thermocouples (needles that measure temperature). Thermocouples are placed at the end of the safety margin, and are essential to perform an accurate freezing. The depth and/or extension can also be controlled by ultrasound, computed axial tomography or nuclear magnetic resonance, essential in cryosurgery of internal organs [50].

After the thawing of the second cycle is completed, superficial and deep infiltration with local anesthetics at the edges of the treated tissue is performed, in order to reduce postoperative discomfort.

\section{Postoperative care}

After recovery from anesthesia, all patient can walk, were able to urinate spontaneously, minimal analgesic requirements, with good postoperative. The patients from the cases presented in this paper had extensive lesions, so they remained in the hospital one day, and, with rare exceptions, were discharged the next one. Washes with physiological solution and sterile dressings are indicated. The first days there is a normal profuse exudate that requires frequent change of dressings depending on the extension of the treated area, approximately every $3 \mathrm{~h}$ or $4 \mathrm{~h}$. From the $3^{\text {rd }}$ or $4^{\text {th }}$ day, a fetid smell may appear due to the necrosis of the treated tissues, which lasts until it spontaneously comes off, in a variable period according to treatment extension. The detachment of the necrotic tissue begins at the edges, and here, the detached areas can be resected to improve the patient's well-being. Central areas is expected, because usually require more time to shed. No antibiotics are indicated, except for particular cases such as: appearance of redness or signs of inflammation in healthy tissues adjacent to the treated area, or, in extensive lesions, in order to reduce the odor of necrotic tissues. The frozen areas do not hurt because freezing destroys pain receptors, but the inflammation of the immediately adjacent tissues can occur, and that small area may cause discomfort. After healing, the receptors are spontaneously repaired and the sensitivity is restored. The postoperative controls are done twice a week until complete healing. The main objective is to prevent synechia, so gentle separation of the treated surfaces in contact must be done. The complete healing time depends on multiple factors: size and depth of the treated area, adequate postoperative care, age, nutritional status, comorbidities, etc. In large tumors, or patients of very advanced age, healing can take 2 to 3 months. Once the healing has been completed, we must treat the lymph nodes according to FIGO standards.

\section{Results}

\section{Follow-up}

Average 58.39 months (6 to 258). Five (12\%) patients had local recurrences in small sectors between 12 and 72 months after treatment and were controlled with new cryosurgery (Table 2). The possibility of repeating cryoablation after a local failure is one of the strengths of this method. Six (14.6\%) patients had HPV related lesions located in other areas of the lower genital tract, which were also controlled with cryosurgery.

Twenty five of them died: 19 due to an unrelated cause of death, and 6 due to disease progression in the nodes without vulvar recurrence. Nine patients survived and were free of disease with a mean follow-up of 53 months. Seven patients, after a disease free follow up of 17.2 months, weren't able to be controlled, as they lived more than $400 \mathrm{~km}$ way from the hospital. Local control was achieved in all patients (Table 2).

\section{Results in terms of sexuality and QOL after cryosurgery}

All local symptoms were controlled: no infection or pain, vulvar sensitivity was preserved, QOL. improved, all patients referred being satisfied with cryosurgery. Healing time: 4 to 12 weeks.

\section{Sexuality}

Twelve were sexually active and evaluable before and posttreatment, nine of them, on an average age of 36.9 years old (28 to Table 3: Restored sexuality.

\begin{tabular}{|c|c|c|c|}
\hline \multirow{2}{*}{ Evaluable } & Restored sexuality & Age (years) & Reset time \\
\hline \multirow{2}{*}{12} & 9 & 36.9 & 4 months \\
\cline { 2 - 4 } & $-75 \%$ & $(28$ to 71$)$ & (3 to 5) \\
\hline
\end{tabular}


71), restarted their sex life in 3 to 5 months after treatment. Table 3 Sexuality was evaluated by FSFI [51].

\section{Discussion}

It is important to highlight that cryosurgery can be performed after any previous treatment, including radiation therapy and it can be repeated as many times as necessary. Cryosurgery, due to the analgesic effect of freezing, is very well accepted by patients, and the postoperative period is well tolerated. Another important aspect is immunologic effects of cryoablation. The release of antigens during the procedure as explained by Claudio et al. [20]:

- "In the era of introduction of immunotherapy in the treatment of various malignancies, increasing interest has been directed toward the cryoablation-induced anti-tumor immune response, which may aid in tumor control and cure. The key point is that antigenic tissue remains in the local ablation. Cryoablation of tumor lesions causes the coagulative necrosis of neoplastic cells. During the thawing phase, tumor cells within the ice ball release in blood circulation intact tumor antigens, as well as other "danger signals", such as nuclear proteins, proinflammatory cytokines, and HMGB1, a molecule that stimulates antitumor immunity response through interactions with Toll-like receptors. These signals act as a stimulus for the natural immune response by attracting macrophages, NK cells, and granulocytes. These cells, in addition, cause cytokines release and dendritic cells, the professional antigen-presenting cells, to reach the cryoablated tissue".

The restoration of the sensitivity of the treated areas is one of the most important factors in the restoration of sexuality. In 2012 we described our results in terms of sexuality and Quality of Life (QOL.) after cryosurgery in patients with pre-neoplastic and neoplastic vulvar lesions [52].

\section{Conclusion}

Although a randomized study was not possible, it was prospective and an interesting number of patients were gathered. Given the simplicity of the technique, its low cost, the possibility of being used in patients with multiple co-morbidities, the absence of complications, and the anatomical and functional results obtained, we believe that cryosurgery can be considered among the first options of treatment for vulvar cancer. Cryosurgery is currently being used in cancers from different locations, and in benign and premalignant pathologies. Although controlled studies are required, in our study the problem was that no patient accepted conventional surgery.

Cryosurgery is an effective and safe method to control these types of lesions in all patients, especially those with comorbidities and multiple previous treatments, and provides several advantages as previously mentioned. Below we include clinical cases with photos that will allow a better understanding of the technique possibilities.

\section{Case 1}

Cryosurgery for treatment of squamous cell carcinoma extended from the pubis to the anus, which recurred after radical surgery: 59-year-old patient, smoker of 40 cigarettes per day from 18 to 49 years old. Background:

1. Conization due to micro-invasive cervix cancer, insufficient margins.

2. Annex-total hysterectomy plus vaginal cuff.

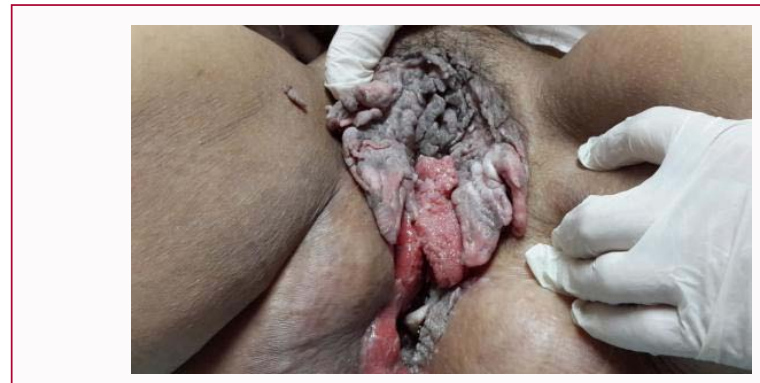

Figure 1: Initial lesion.

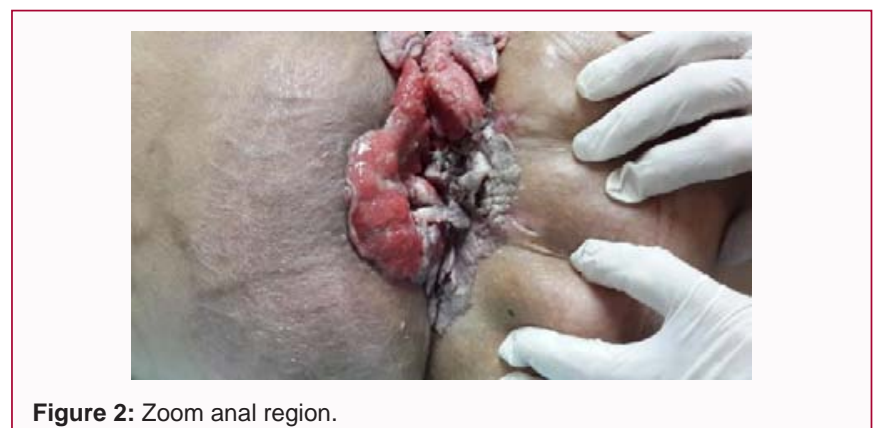

Figure 2: Zoom anal region.
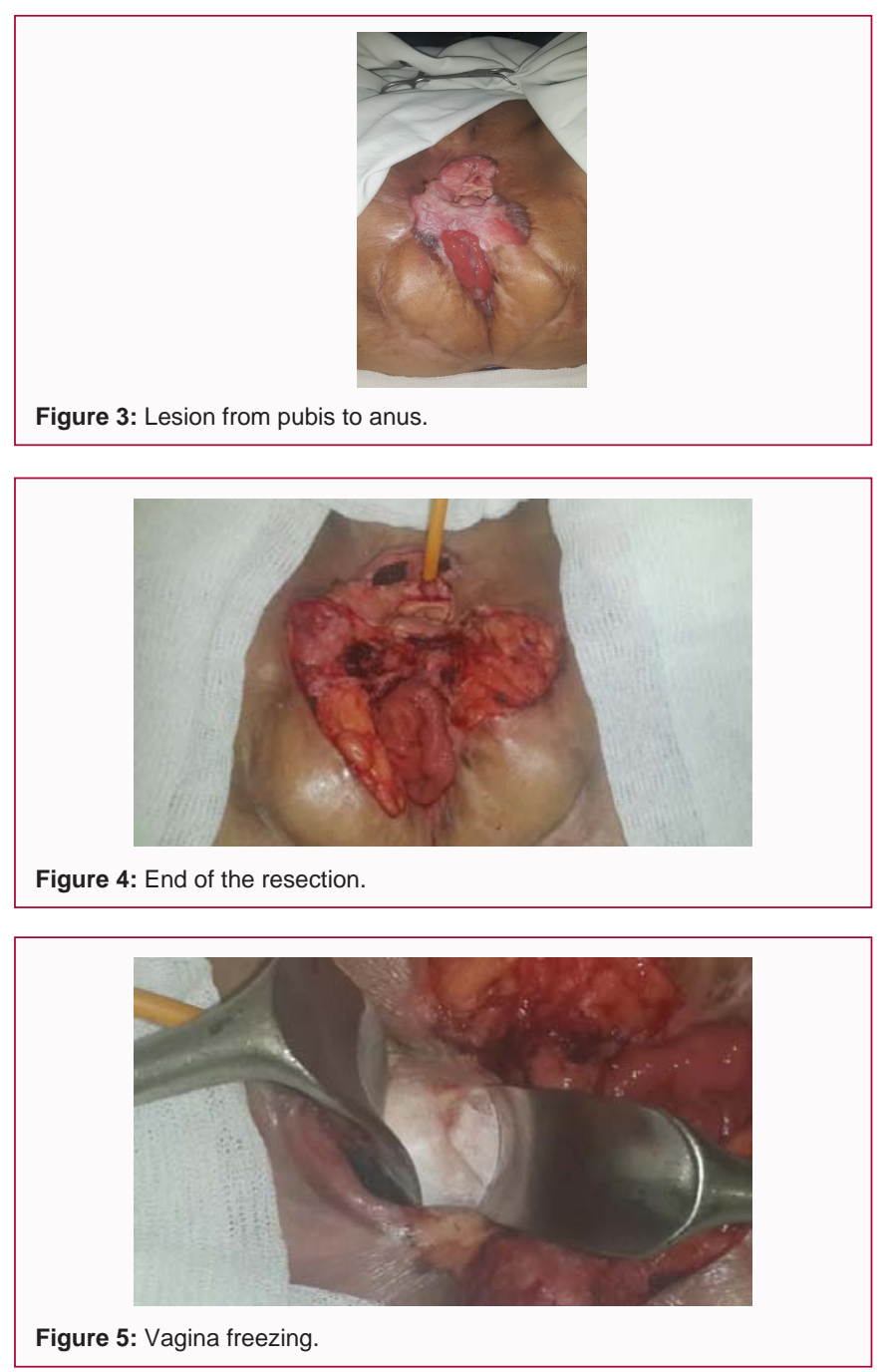

3. Vulvar and perianal cancer (Figure 1 and 2). The patient had been treated in another center with radical surgery, and required 

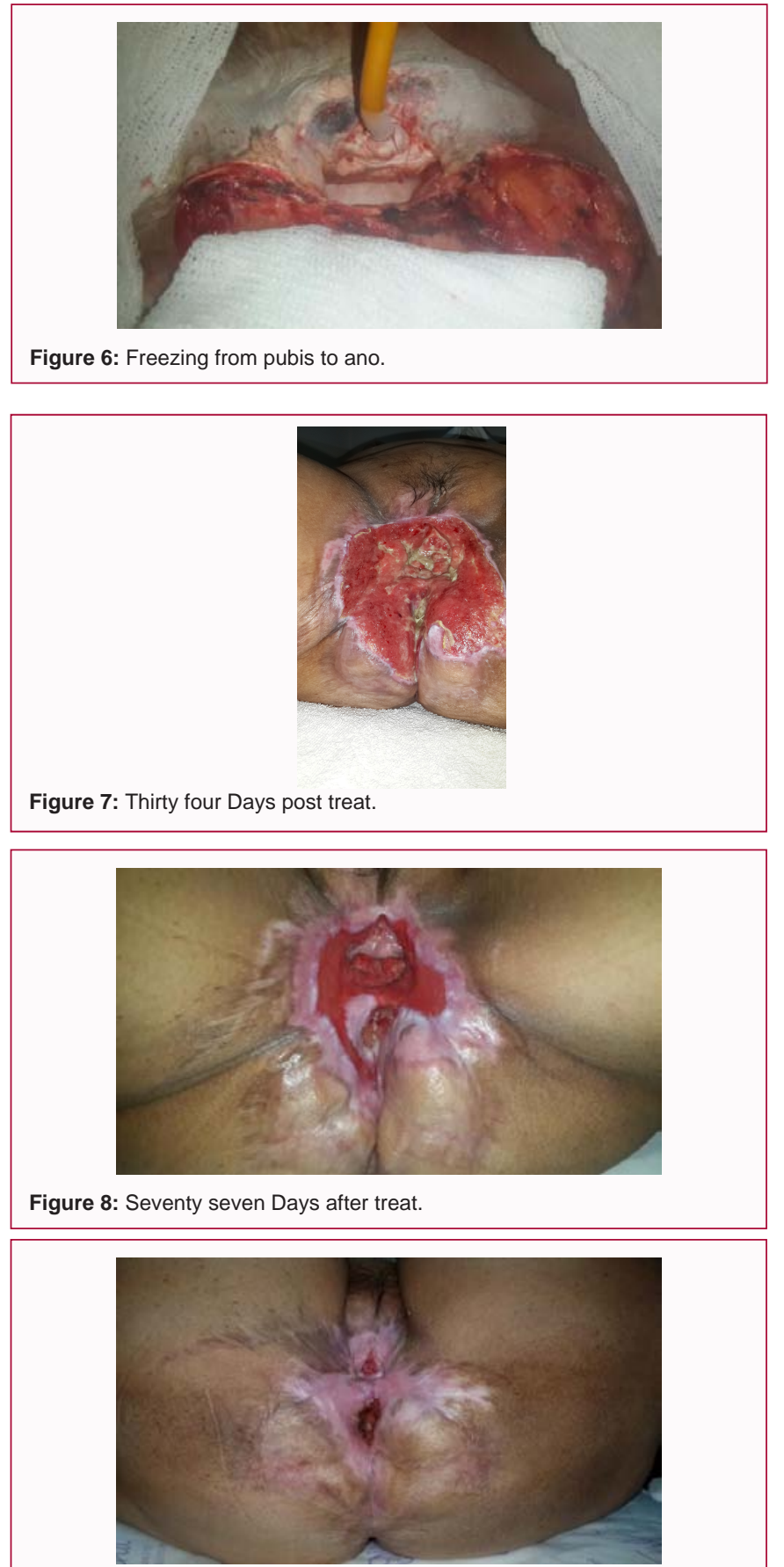

Figure 9: Two Years after cryosurgery.

rotating flaps.

4. Recurrence in the pubic region, vulva, vagina and perianal (Figure 3), very difficult to treat with common techniques.

Treatment: Radiofrequency resection (Figure 4) plus cryosurgery in the vagina (Figure 5), and externally from pubis to perineum (Figure 6). After 34 and 77 days (Figure 7 and 8). Control of 2 years after treatment no lesions were observed (Figure 9).

\section{Case 2}

A 32 year old patient HIV+, poor adherence to antiretroviral treatment, drug addict, smoker of 40 cigarettes per day.

Diagnosis: Grade III intraepithelial neoplasia in the cervix and
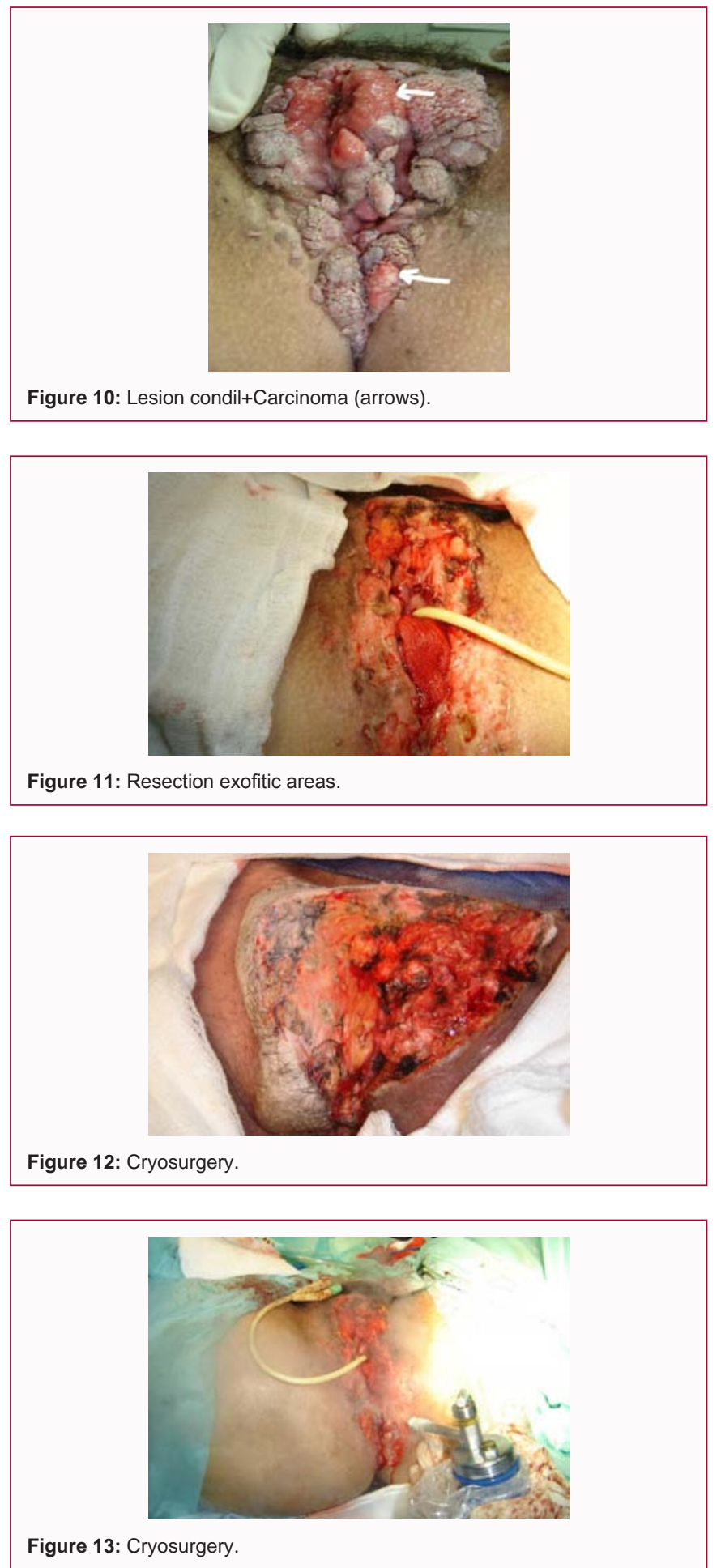

vagina, condylomata acuminata and multi-centric squamous cell carcinoma in vulva (Figure 10).

Treatment: Cryosurgery of the cervix and vagina. In vulva resection of exophytic areas + cryosurgery (Figures 11-13), two freeze-thawing cycles. She did not accept lymphadenectomy. She abandoned control and treatment. She returned 10 months after treatment without lesions in treated areas (Figure 14), with a huge progression in the inguinal lymph nodes (Figure 15), which did not respond to resection of the possible reduction areas, chemo and radiotherapy. However (Figure 16) the result in the vulva remained, 

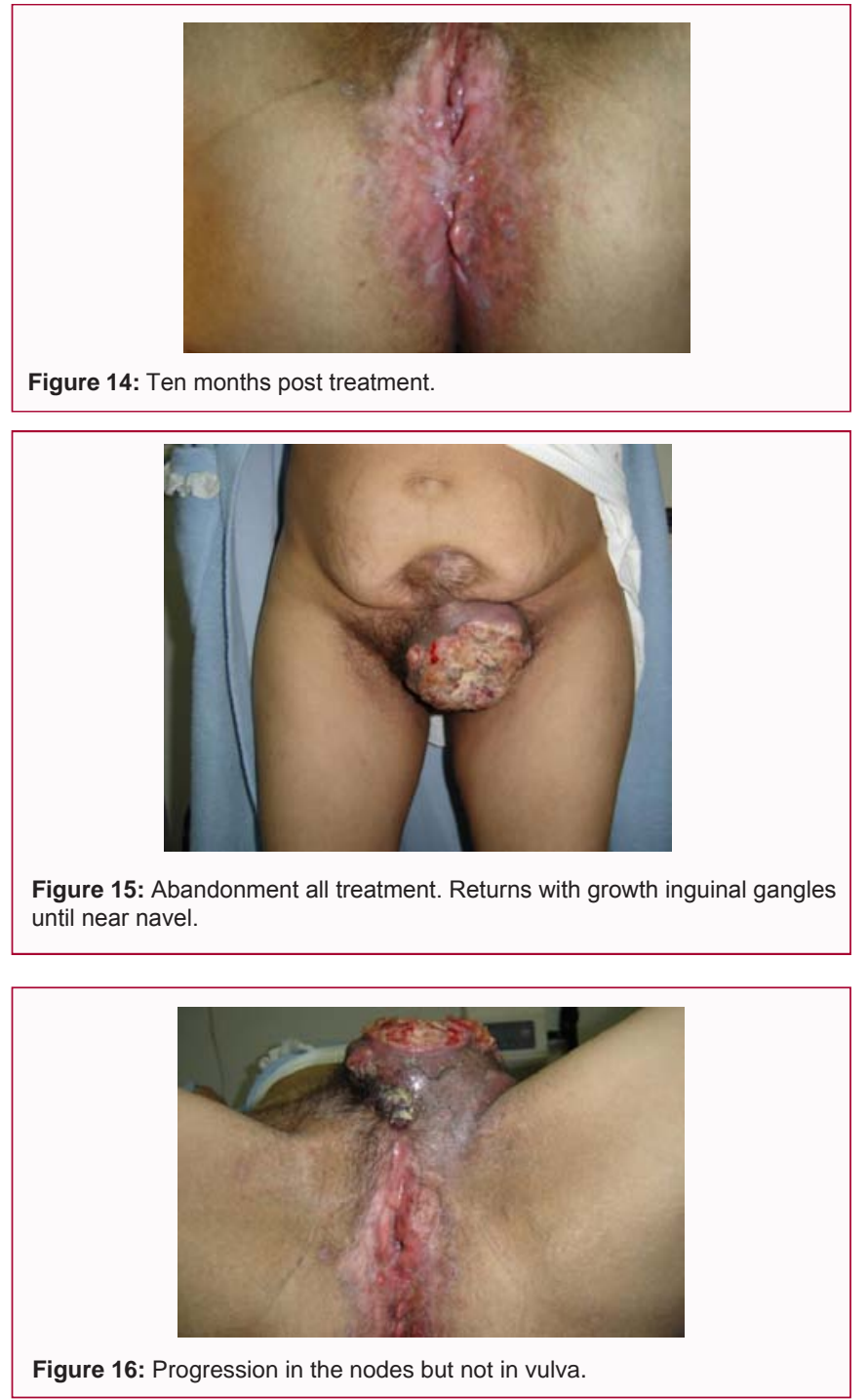

one year after the local treatment, as seen before and after treatment (Figure 16). The patient died 12 months after cryosurgery but without vulvar lesion. This case is presented to show how, despite the progress of the disease in the nodes (which were restricted from the right treatment by the patients will), in a patient with very important risk factors, the local control in the vulva was not modified.

\section{Case 3}

A 90 year-old women, moderately differentiated squamous cell carcinoma FIGO stage IVA, with multiple co-morbidities: Age, diabetes, high blood pressure. We can see lesion (Figure 17), tumor measuring: $6 \mathrm{~cm}$ in diameter and in depth (Figure 18 and 19), in the

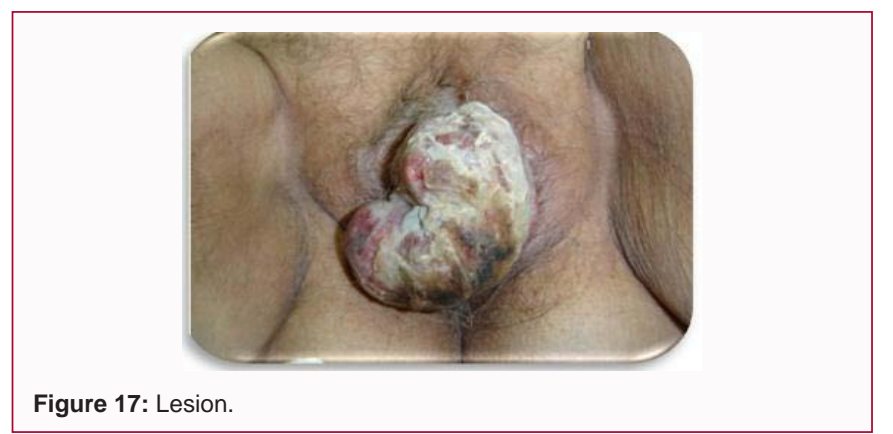

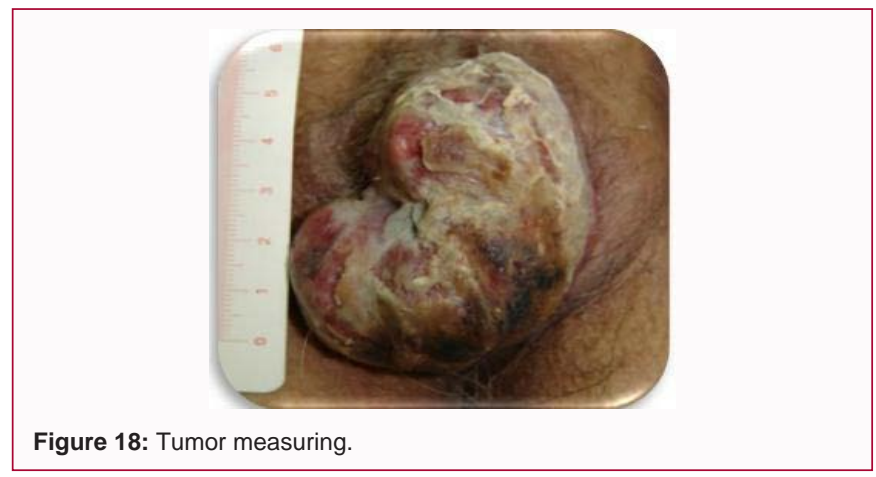
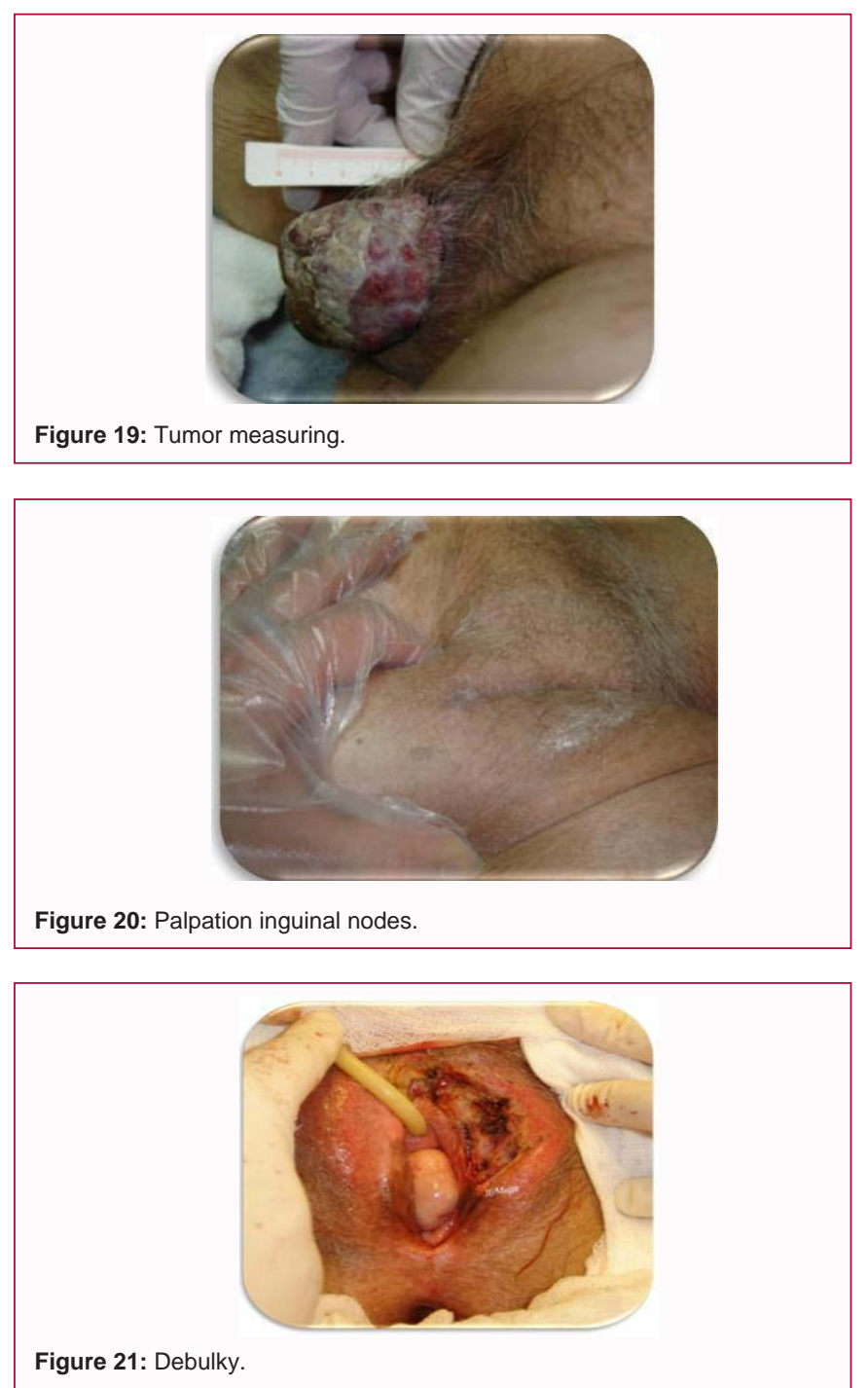

right inguinal region, palpable lymphadenopathiy of about five by four centimeters, fixed to deep planes (Figure 20). The tumor was infected, smelling foul, bleeding frequently and making urination difficult. The pain prevented her from sitting, all of which caused a poor quality of life.

Treatment: Tumor debulking (Figure 21) and freezing including lodge, safety margins and low third of urethra (Figure 22).

Evolution: At day five: Necrosis (Figure 23), and at day nineteen: Necrotic areas spontaneously detached, and granulation tissue observed (Figure 24). Patient did not refer pain, or analgesic 

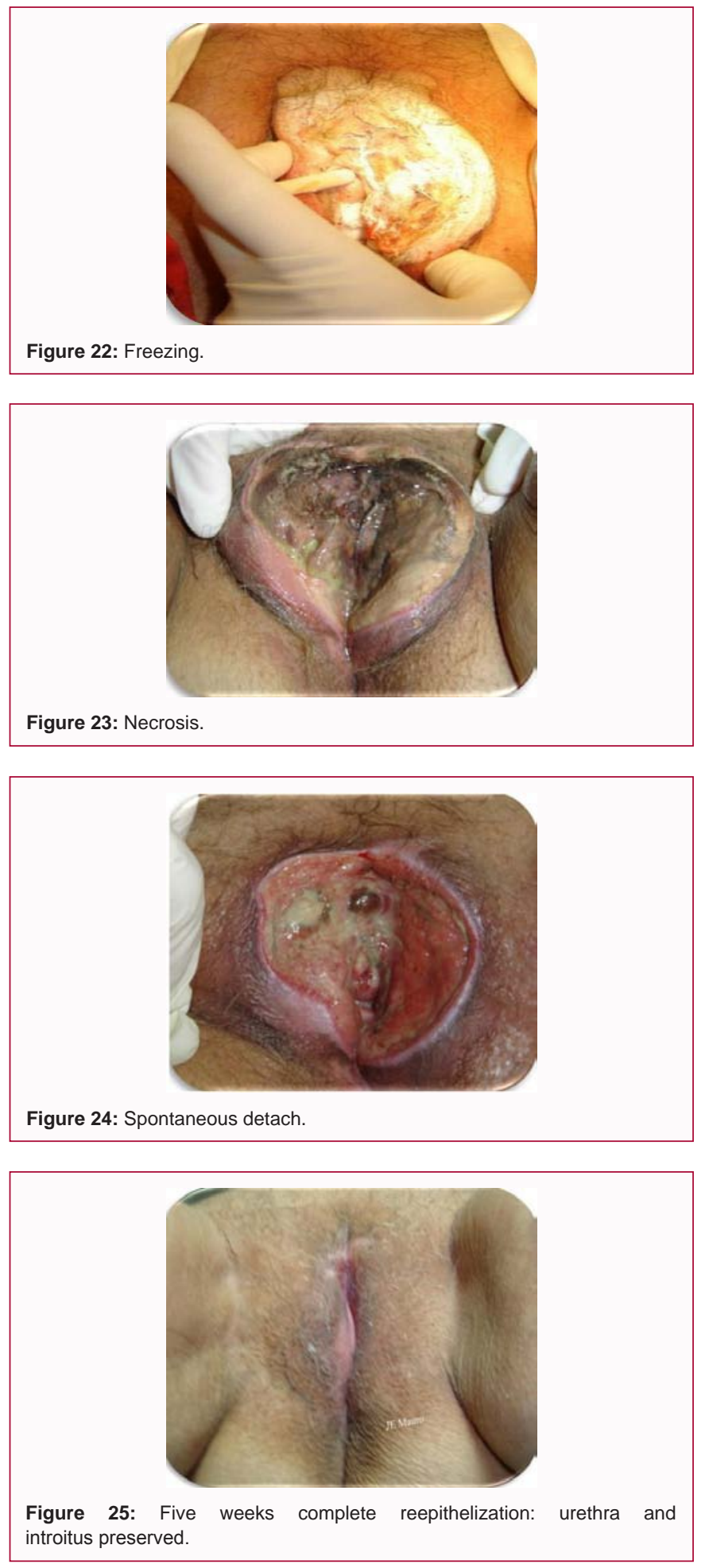

requirement, with spontaneous urination.

Follow up: 5 weeks complete healing: urethra and vulva preserved (Figure 25, 26). She had a great improvement in her quality of life: Control of pain, infection, bleeding, urinating and sitting difficulty. It also decreased the burden on their caregivers. She died of pulmonary thromboembolism caused by lymphadenopathy, which could not be treated due to her age and general condition, without lesions in the treated areas; 17 months post treatment (Figure 27).
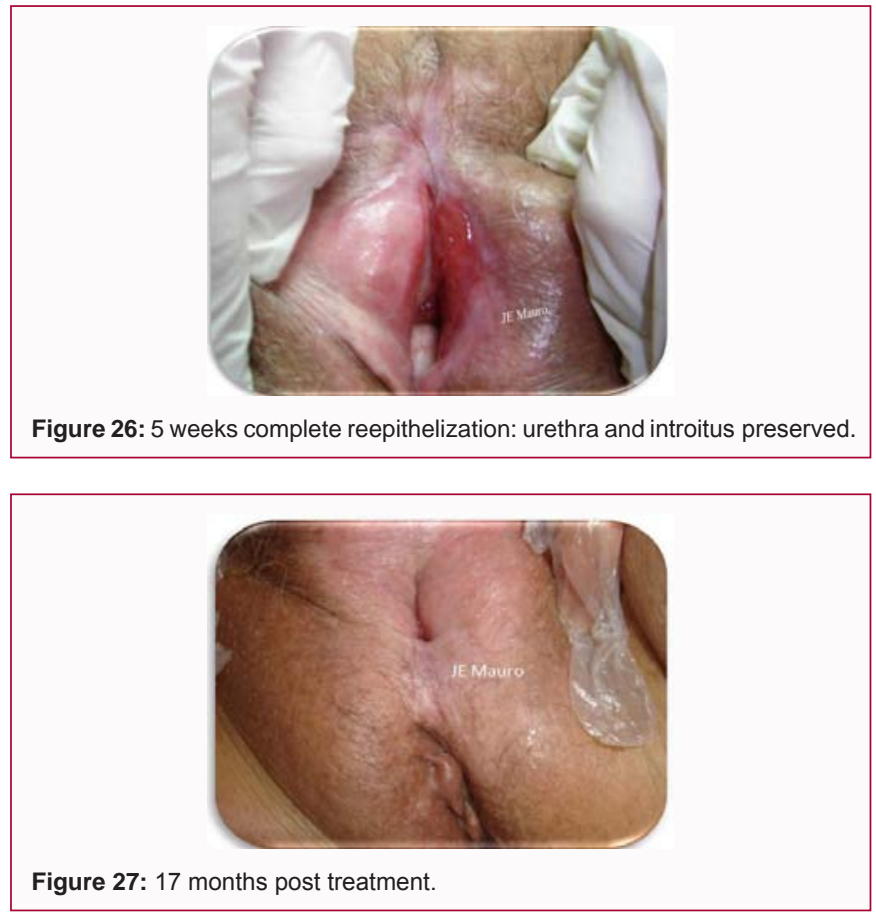

\section{Case 4}

A 71-year-old patient, hypertensive, well-differentiated FIGO stage IIIC squamous cell carcinoma (Figure 28, 29). Radiofrequency resection (Figure 30) plus cryosurgery (Figure 31) was performed. Temperature monitoring (Figure 32), 5 days post-treatment (Figure 33) necrosis. Good postoperative evolution. After complete healing at 10 weeks postoperative (Figure 34), bilateral inguinal and femoral
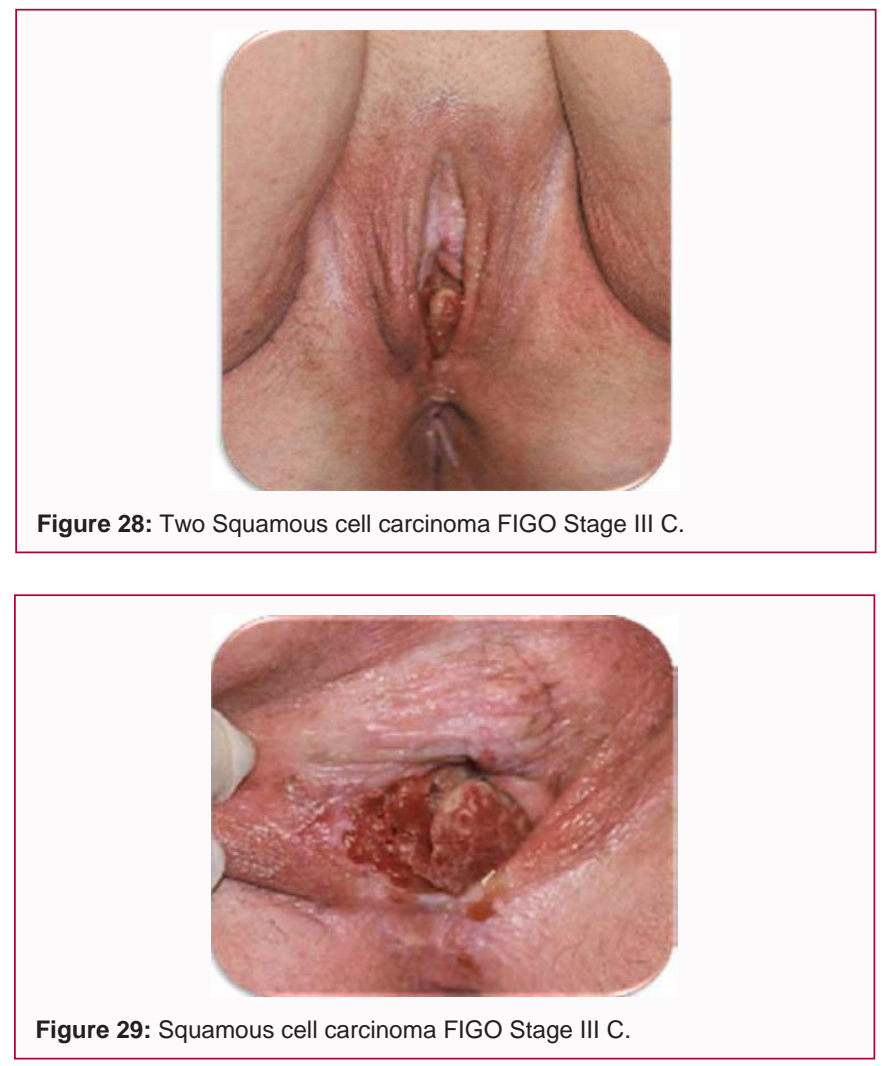

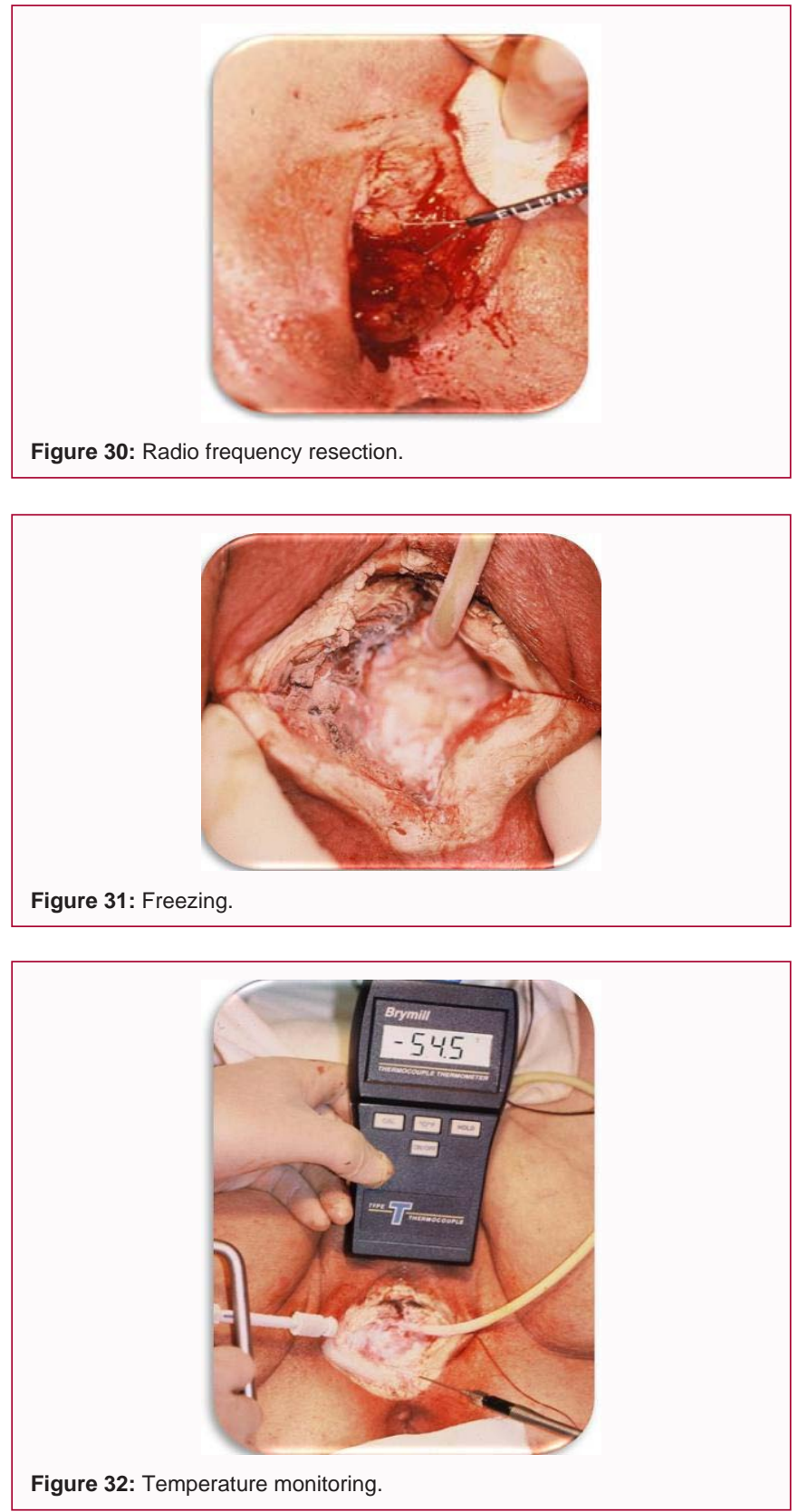

lymphadenectomy was performed: $2 / 14$ positive nodes, with capsular rupture. Inguinal and pelvic radiation therapy. Good evolution. He had a stable partner and restarted his sexual life 3 months after treatment ended. Follow-up (Figure 35) 5 years without recurrences. She died of an unrelated cause (stroke) at 76 years free of genital disease.

\section{Acknowledgements}

To all members of the Departments of Gynecology and Oncology, CG Durand Hospital, where all patients were treated.

- To our masters in cryosurgery: Doctors Eliezer Turjansky and Esther Stolar, founders of the Argentine Society of Cryosurgery, who shared their great experience.

- To International Society of Cryosurgery, in whose congresses we can present and share the results obtained in different
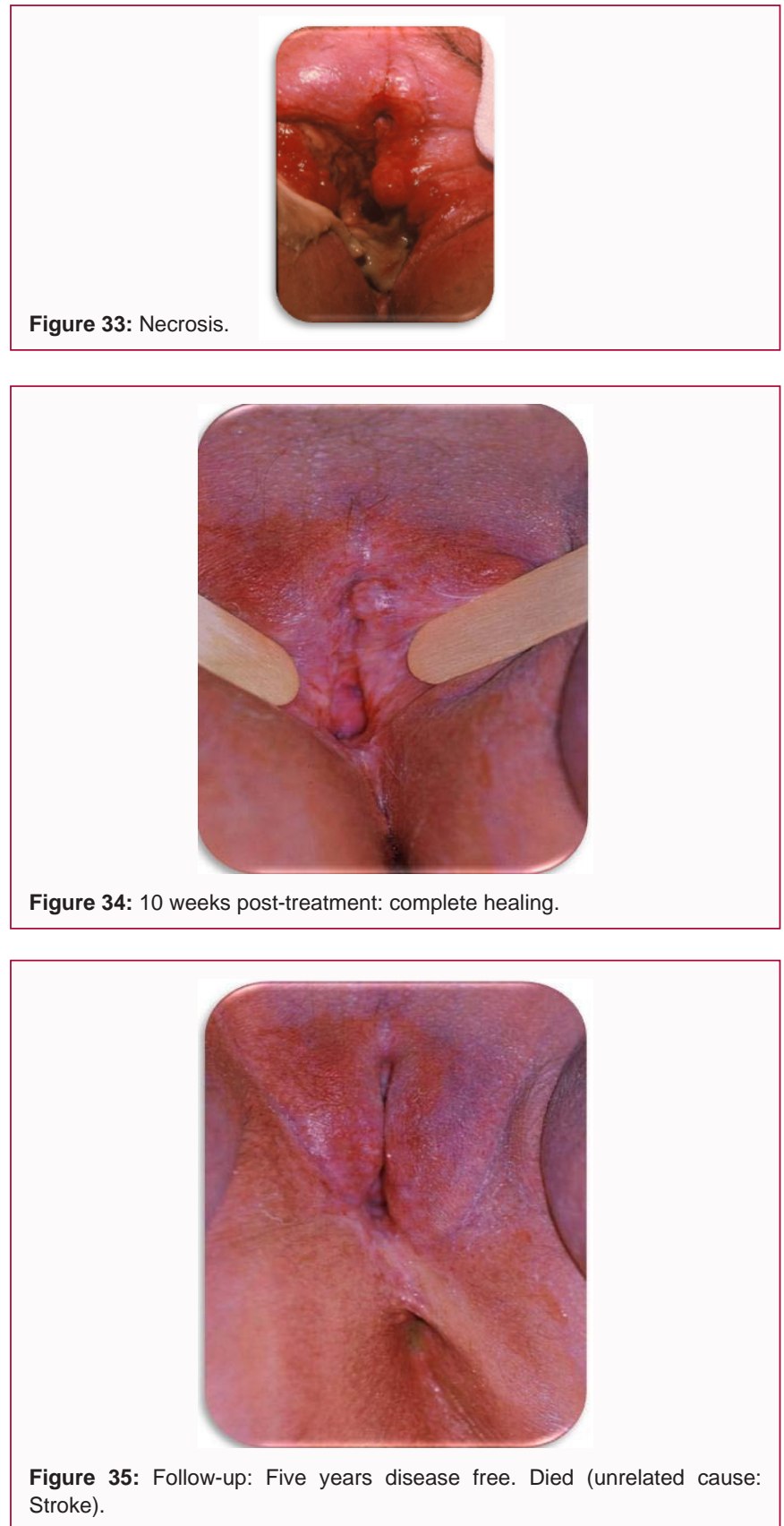

medical specialties and update technological advances.

- To our masters of Lower Genital Tract Pathology and Colposcopy doctors

- Armando E. Guglielminetti, Carlos Jakob and Juan C. Balparda, pioneers in the introduction of colposcopy and the study of the lower genital tract, and the growth of Argentine Society of Pathology of the Lower Genital Tract and Colposcopy (SPTGIyC).

- To Dr. Maria Victoria Bertolino, for her invaluable contribution in the evaluation of vulvar sensitivity and sexuality before and after treatment, and her comments to the paper.

- To the patients, who trusted us.

- Last but not least to our families, who encouraged and helped at all times. 


\section{References}

1. Blanca RC, Karen KSM, Michelle JK. Does treatment for cervical and vulvar dysplasia impact women's sexual health? Am J Obstet Gynecol. 2015;212(3):291-7.

2. Kuflik EG. Cryosurgery for skin cancer: 30 years of experience and cure rates. Dermatol Surg. 2004;30(2 pt 2):297-300.

3. Boullie M. Cryosurgery in dermatology. Cryosurgery-mechanism and applications. Int Institute Refrigeration. 1995;8:87-95.

4. Fernandes Rodriguez RB. Cryosurgery in the treatment of advanced tumors of the skin and of the vulva. Cryosurgery- mechanism and applications. Int Institute Refrigeration. 1995;10:105-11.

5. Lee CN, Pan SC, Yu-Yun JL, Wong TW. Successful treatment of cutaneous squamous cell carcinoma with intra-lesional cryosurgery: Case report. Medicine (Baltimore). 2016;95(39):e4991.

6. Duffey B, Nguyen V, Lund E, Koopmeiners Js, Hulbert J, Anderson Jk Intermediate-term outcomes after renal cryoablation: Results of a multiinstitutional study. J Endourol. 2012;26(1):15-20.

7. Atwell TD, Carter RE, Schmit GD, Carr CM, Boorjian SA, Curry TB et al. Complications after 573 percutaneous renal radiofrequency and cryoablation procedures. J Vasc Interv Radiol. 2012;23(1):48-54.

8. Long CJ, Canter DJ, Smaldone MC, Li T, Simhan J, Rozenfeld B, et al. Review of the role of tumor location in patient selection for percutaneous versus surgical cryoablation of renal masses. Can J Urol. 2012;19(5):641722 .

9. Zargar H, Samarasekera D, Khalifeh A, Remer Em, O'malley C, Akca O, et al. Laparoscopic $v s$. percutaneous cryoablation for the small renal mass: 15-year experience at a single center. Urology. 2015;85(4):850-5.

10. Rodriguez Faba O, Sanguedolce F, Grange P, Kooiman G, Bakavicius A, De La Torre P, et al. Kidney cancer focal cryoablation trend: Does location or approach matter? World J Urol. 2016;34(7):917-23.

11. Annemarie U, Oliver H, Strauss A, Joachim L, Lutz T, René MW, et al. Treatment for localized T1a clear cell renal cell carcinoma: Survival benefit for cryosurgery and thermal ablation compared to deferred therapy. Cardiovasc Intervent Radiol. 2018;41(2):277-83.

12. Forest V, Peoc HM, Campos L, Guyotat D, Vergnon JM. Benefit of a combined cryotherapy and chemotherapy treatment on tumor growth and late cryo-induced angiogenesis in a model of non-small-cell lung cancer model. Lung cancer. 2006;54(1):79-86.

13. Lee HS, Choi JW, Sung WS, Kim KY, Kim HC, Zo IJ, et al. Endoscopic cryotherapy of lung and bronchial tumors: A systematic review. Korean J Intern Med. 2011;26(2):137-44.

14. Bang HJ, Littrup PJ, Currier BP, Goodrich DJ, Aoun HD, Klein LC, et al Percutaneous cryoablation of metastatic lesions of non-small cell lung carcinoma: Baseline survival, local control, and cost observations. J Vasc Interv Radiol. 2012;23(6):761-9.

15. Niu L, Xu K, Mu F. Cryosurgery for lung cancer. J Thorac Dis. 2012;4(4):408-19.

16. Yuanying Y, Lizhi N, Feng M, Xiaohua W, Jianying Z, Fei Y, et al Therapeutic results of the combination of cryotherapy, chemotherapy and DC-CIK immunotherapy in the treatment of metastatic non-small cell lung cancer. Cryobiology. 2013;67(2):235-40.

17. Inoue M, Nakatsuka S, Jinzaki M. Cryoablation of early-stage primary lung cancer. Biomed Res Int. 2014;2014:521691.

18. Pfleiderer SO, Marx C, Camara O, Gajda M, Kaiser WA. Ultrasoundguided percutaneous cryotherapy of small $(<$ or $=15 \mathrm{~mm})$ breast cancers. Invert Radiol. 2005;40(7):472-7.

19. Littrup PJ, Jallad B, Chandiwala-Mody P, D'agostini M, Adam BA, Bouwman D. Cryotherapy for breast cancer: A feasibility study without excision. J Vasc Interv Radiol. 2009;20(10):1329-41.

20. Claudio P, Panagiotis P, Giuseppe N, Alessandro F. Cryoablation in the management of breast cancer: Evidence to date. Breast Cancer (Dove Med Press). 2019;11:283-92.

21. Holmes RD. Breast cancer care during a pandemic: A timely time for cryoablation? Breast Cancer Res Treat. 2020;182(3):515-21.

22. Sommer J, Renziehausen K, Neuhauser H, Neuhauser M, Hecker J. [Potentials and limits of cryosurgery of vulvar cancer -- Results of therapy at 12 years' results of therapy. Zentralbl Gynakol. 1986;108(11):649-58.

23. Almeida Goncalvez JC. Cryovulvectomy - a new surgical technique for advanced cancer. Skin Cancer. 1986;1:17-32.

24. Tixeira JM. Cryosurgery in gynecology. Cryosurgery. Int Institute Refrigeration. Malesherbes. 1995;11:111-9.

25. Berek JS, Hacker NF. Vulvar cancer. $4^{\text {th }}$ Ed. Practical Gynecologic Oncology Hacker NF. 543-83.

26. Mauro JE. Cryosurgery for local control of vulvar cancer. Modern Cryosurgery for Cancer. Kecheng Xu, Nikolai N, Korpan, Lizhi Niu. Singapore: World Scientific Publishing. 2012;(37):695-714.

27. Greenwald BD, Dumot JA. Review cryotherapy for Barrett's esophagus and esophageal cancer. Curr Opin Gastroenterol. 2011;27(4):363-7.

28. Ke-Cheng Xu, Li-Zhi Niu, Xiangjun Bi, Bin Cao. Cryosurgery for Abdominal tumors. Editors: Kecheng Xu, Nikolai N. Korpan, Lizhi Niu. Part 4. Modern Cryosurgery for Cancer. 2012;(31):575-96.

29. Ji-Bing C, Li JL, He LH, Liu WQ, Fei Y, Zeng JY, et al. Radical treatment of stage IV pancreatic cancer by the combination of cryosurgery and iodine-125 seed implantation. World J Gastroenterol. 2012; 18(47):705662.

30. Gang Z, David C, Qin D, Lizhi N, Jinlei C, He L, et al. Expression of CD44v6 and integrin- $\beta 1$ for the prognosis evaluation of pancreatic cancer patients after cryosurgery. Diagn Pathol. 2013;8:146.

31. Lihua H, Lizhi N, Nikolai NK, Sajio S, Yueyong Xiao, Jiaping Li, et al. Clinical practice guidelines for cryosurgery of pancreatic cancer" consensus statement from the China cooperative group of cryosurgery on pancreatic cancer, International society of cryosurgery, and Asian society of cryosurgery. Pancreas. 2017;46(8):967-72.

32. Gage A, Snyder K, Baust JM. Selective cryotherapy: Preservation-ablation. In: Baust JG, Baust JM, editors. Advances in bio-preservation. $1^{\text {st }}$ Ed. CRC Press; Boca Raton, FL: 2007.

33. Mcwilliams JP, Yamamoto S, Raman SS, Loh CT, Lee EW, Liu DM, et al. Review Percutaneous ablation of hepatocellular carcinoma: Current status. J Vasc Interv Radiol. 2010;21(8 Suppl.):S204-13.

34. Chen HW, Lai EC, Zhen ZJ, Cui WZ, Liao S, Lau WY. Ultrasoundguided percutaneous cryotherapy of hepatocellular carcinoma. Int J Surg. 2011;9(2):188-91.

35. Ng KM, Chua TC, Saxena A, Zhao J, Chu F, Morris DL. Two decades of experience with liver cryotherapy for advanced colorectal metastases. Ann Surg Oncol. 2012;19(4):1276-83.

36. Clarke DM, Baust JM, Van Buskirk RG, Baust JG. Chemo-cryo combination therapy: A complementary model for the treatment of prostate cancer. Cryobiology. 2001;42(4):274-85.

37. Clarke DM, Robilotto AT, Van Buskirk RG, Baust JG, Gage AA, Baust JM. Targeted induction of apoptosis through trail and cryoablation: A new strategy for the treatment of prostate cancer. Prostatic Dis Prostate Cancer. 2007;10(2):175-84

38. Seok Cho, Seok Ho K. Current status of cryotherapy for prostate and kidney cancer. Korean J Urol. 2014;55(12):780-8.

39. Liang G, Lu Y, Shengqiang Q, Zhuang T, Feng Q, Qiang W, et al. 
Cryosurgery would be an effective option for clinically localized prostate cancer: A meta-analysis and a systematic review. Sci Rep. 2016;6:27490.

40. Mingxiong S, Lingling W, Changming L, Liu C. Is cryosurgery a feasible local therapy for metastatic bone prostate cancer? Singapore Med J. 2018;59(11):584-9.

41. Jian S, Yuan L, Shuzhen L, Jianying Z, Guifeng L, Feng M, et al. Analysis of circulating tumor cells in patients with liver metastases with colorectal cancer before and after cryosurgery. Cancer Biol Ther. 2016;17(9):935-42.

42. Xu CK, Li-Zhi N, He BW, Hu ZY, Zuo SJ. Percutaneous cryosurgery for the treatment of hepatic colorectal metastases. World J Gastroenterol. 2008;14(9):1430-6

43. Kecheng Xu, Zongyuan Z. Cryosurgery for head and neck tumors. Part 4. Kecheng Xu, Nikolai NK, Lizhi N, editors. Modern Cryosurgery for Cancer. 2012;(39):759-70.

44. Mauro JE. Possibilities of radiofrequency and cryosurgery in the treatment of vulvar cancer. Cryosurgery. World Congress of Cryosurgery in Paris. 1995:59:543.

45. Mauro JE, Bertolino MV, Basilio F, Nassif JC, Jankilevich G. A series of 21 cases using cryosurgery, a novel technique for managing advanced or extended vulvar cancer in medically debilitated patients. Gynecol Oncol. 2009;114(4):542-3
46. Pathak S, Jones R, Tang JM, Parmar C, Fenwick S, Malik H, et al. Review ablative therapies for colorectal liver metastases: A systematic review. Colorectal Dis. 2011;13(9):e252-65.

47. Baust JM, Rabin Y, Polascik JT, Santucci LK, Snyder KK, Van Buskirk RG, et al. Defeating adaptive cancer defense strategies using thermal therapies: examining cancer therapeutic, ablative, and computational modeling resistance strategies as a means of improving therapeutic outcome. Technol Cancer Res Treat. 2018;17:1533033818762207.

48. Sandison GA, Loye MP, Rewcastle JC, Hahn LJ, Saliken JC, McKinnon JG, et al. CT X-ray monitoring of ice ball growth and thermal distribution during cryosurgery. Phys Med Biol. 1998;43(11):3309-24.

49. Wilkins KM, Warnock JK. Primary psychiatry. 2009;16(3).

50. Kecheng Xu, David C, Cho T, Wesely S. Overview of cryosurgery for tumors. In: Part 2. Kecheng Xu, Nikolai NK, Lizhi Niu, editors. Modern Cryosurgery for Cancer. 2012:103-22.

51. Mahnken AH, König AM, Figiel JH. Current technique and application of percutaneous cryotherapy. Rofo. 2018;190(9):836-46.

52. Mauro JE, Bertolino MV, Caffoni M, Morin A. Sexual function and quality of life in patients with vulvar pre-neoplastic and neoplastic pathology treated with cryosurgery. J Sexual Med. 2012;90;70-1. 